\title{
Correction to: Informal healthcare provision in Lebanon: an adaptive mechanism among displaced Syrian health professionals in a protracted crisis
}

Gladys Honein-AbouHaidar ${ }^{1,2}$, Aya Noubani ${ }^{1}$, Nour El Arnaout ${ }^{1}$, Sharif Ismail ${ }^{3}$, Hana Nimer ${ }^{1}$, Marilyne Menassa $^{1}$, Adam P. Coutts ${ }^{4}$, Diana Rayes ${ }^{5}$, Lamis Jomaa ${ }^{1,6}$, Shadi Saleh ${ }^{1,7}$ and Fouad M. Fouad ${ }^{1,8^{*}}$

\author{
Correction to: Confl Health \\ https://doi.org/10.1186/s13031-019-0224-y
}

The original publication of this article [1] contained an incomplete funding section. The full funding section is listed in this correction article. The missing information is indicated in bold.

\section{Funding}

This study was funded by the Collaborative Research Stimulus at the American University of Beirut, Lebanon, and by an accountable grant from the International Institute for Environment and Development (IIED) in the UK [grant no. 719.10/42, and through the UK Research and Innovation GCRF RESEARCH FOR HEALTH IN CONFLICT (R4HC-MENA); developing capability, partnerships and research in the Middle and Near East (MENA) ES/P010962/1.

\section{Author details}

${ }^{1}$ Global Health Institute, American University of Beirut, Beirut, Lebanon. ${ }^{2}$ Hariri School of Nursing, American University of Beirut, Beirut, Lebanon. ${ }^{3}$ Department of Primary Care and Public Health, Imperial College London, London, UK. ${ }^{4}$ Department of Sociology and Magdalene College, University of Cambridge, Cambridge, UK. ${ }^{5}$ Syria Public Health Network, London, UK. ${ }^{6}$ Department of Nutrition and Food Sciences, Faculty of Agricultural and Food Sciences, American University of Beirut, Beirut, Lebanon. 'Department of Health Management and Policy, Faculty of Health Sciences, American University of Beirut, Beirut, Lebanon. ${ }^{8}$ Department of Epidemiology \& Population Health, Faculty of Health Sciences, American University of Beirut, P.O. Box 11-0236, Riad El Solh, Beirut 1107 2020, Lebanon.
Published online: 08 October 2019

Reference

1. Honein-AbouHaidar G, Noubani A, El Arnaout N, et al. Informal healthcare provision in Lebanon: an adaptive mechanism among displaced Syrian health professionals in a protracted crisis. Confl Health. 2019;13:40 https:/ doi.org/10.1186/s13031-019-0224-y.

* Correspondence: mm157@aub.edu.lb

1 Global Health Institute, American University of Beirut, Beirut, Lebanon

${ }^{8}$ Department of Epidemiology \& Population Health, Faculty of Health

Sciences, American University of Beirut, P.O. Box 11-0236, Riad El Solh, Beirut

1107 2020, Lebanon

Full list of author information is available at the end of the article

(c) The Author(s). 2019 Open Access This article is distributed under the terms of the Creative Commons Attribution 4.0 International License (http://creativecommons.org/licenses/by/4.0/), which permits unrestricted use, distribution, and reproduction in any medium, provided you give appropriate credit to the original author(s) and the source, provide a link to the Creative Commons license, and indicate if changes were made. The Creative Commons Public Domain Dedication waiver (http://creativecommons.org/publicdomain/zero/1.0/) applies to the data made available in this article, unless otherwise stated. 